\title{
Sustainable Development of Geothermal Industry in China: An Overview
}

\author{
Bang $X \mathrm{u}^{1, a}$, Menggang $\mathrm{Li}^{1}$, Xiyu $\mathrm{Pi}^{2,3}$ \\ ${ }^{1}$ Postdoctoral research station of China Industry Safety Research Center, Beijing Jiao tong university, Beijing \\ 100044, China \\ ${ }^{2}$ State Key Laboratory of High-efficiency Mining and Safety of Metal Mines, Ministry of Education, University of \\ Science and Technology Beijing, Beijing 100083, China; \\ ${ }^{3}$ School of Civil and Environment Engineering, University of Science and Technology Beijing, Beijing 100083, \\ China
}

\begin{abstract}
With a wide distribution, large reserves, low cost, sustainable energy use and environmental protection and other unparalleled advantages, geothermal energy resources is important for China's energy structure adjustment, energy conservation and environment improvement . Currently, geothermal utilization in China is still in its infancy, and Sustainable Development of the geothermal industry is also having a lot of problems. In this paper, the current research on sustainable development of geothermal industry focuses on two aspects: 1 . the current situation of geothermal industry development and existing problems, 2 . the current situation of sustainable development of the geothermal industry. On the basis of the review, some suggestions for further study on the sustainable development of geothermal industry are put forward.
\end{abstract}

\section{Introduction}

In the 21st century, with the rapid development of Chinese social economic and continuous growth of population, energy consumption increased significantly, traditional fossil energy resources such as coal, oil, gas are dwindling, and as a consequence the environmental degradation increasingly apparent. Adjustment of energy consumption structure, need for energy conservation and environmental protection, development and utilization of renewable energy is increasingly attract the attention of the whole society [1]. Geothermal resources, as one of the new energy resources, with a wide distribution, large reserves, low cost, Sustainable Utilization, environmental friendly and other unparalleled advantages, if can be fully exploited, it will save a lot of traditional fossil energy such as coal, oil and gas, which will be of great significance to improve Chinese energy structure and solve the increasingly serious environmental problems [2]. However, in the process of the development and utilization of geothermal resources in China exists many problems, such as the low degree of development and utilization, serious waste of resources, outdated management situation, and the thermal pollution, harmful gas pollution, chemical pollution, high fluoride, soil hardening and salinization during exploitation, the thermal reservoir water table drop caused by the unreasonable exploitation is also more prominent [3], doing research on sustainable development of geothermal

\footnotetext{
${ }^{a}$ Corresponding author : bxu2@uwyo.edu
} 
resources in China, realizing the ecological, economic and social coordinated development, prolong the life of the development and utilization of geothermal resources are of great significance to promote the healthy development of geothermal energy industry in China [4].

At present, the academic research on the sustainable development of geothermal industry in China is mainly concentrated in two aspects: one is the present situation and problems in geothermal industry, the other is the evaluation of the sustainable development of the geothermal industry and the development strategy research. This article will systematically introduce the sustainable development of geothermal industry in China from the above two aspects.

\section{Review of the Current Development of Geothermal Industry in China}

Geothermal industry refers to enterprises and institutions aggregate that participate in a series of process activities such as geothermal resource exploration, development and application [5]. In general, the geothermal industry chains in China are as shown in figure 1. Geothermal exploration evaluation is the basis of geothermal industry, and geothermal resources exploitation and utilization way is the key of the geothermal industry development.

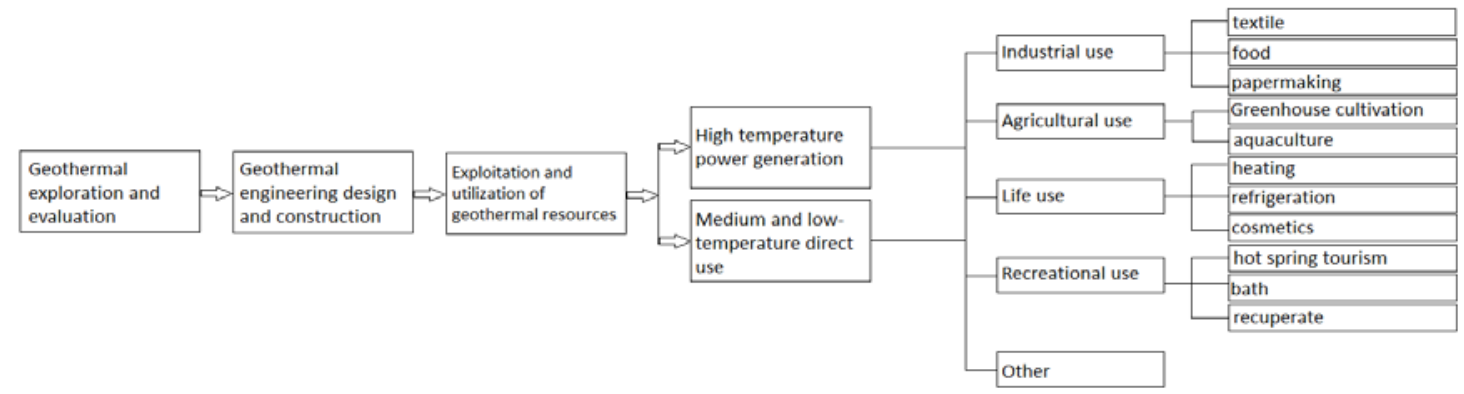

Figure 1. Geothermal industry chains in China[6]

Geothermal resource is the available geothermal energy, geothermal fluid and its useful components for development and utilization in shallow crust under the condition of current technology economy and geological environment, it is a kind of clean and renewable energy [6, 7]. According to its properties can be divided into three types: high temperature $\left(>150{ }^{\circ} \mathrm{C}\right)$ convection type geothermal resources, mainly distributed in southern Tibet, western Sichuan, western Yunnan and Taiwan; Medium temperature $\left(90 \sim 150{ }^{\circ} \mathrm{C}\right)$ and low temperature $\left(<90{ }^{\circ} \mathrm{C}\right)$ convection type geothermal resources, mainly distributed in Guangdong, Hainan, Fujian and other provinces; Medium and low temperature conduction type geothermal resources, mainly distributed in northern China, Sichuan, Songliao, Ordos, etc. [8-10]. The temperature distribution of land area $5.5 \mathrm{~km}$ deep geothermal resources in China are shown in figure 2 as follows.

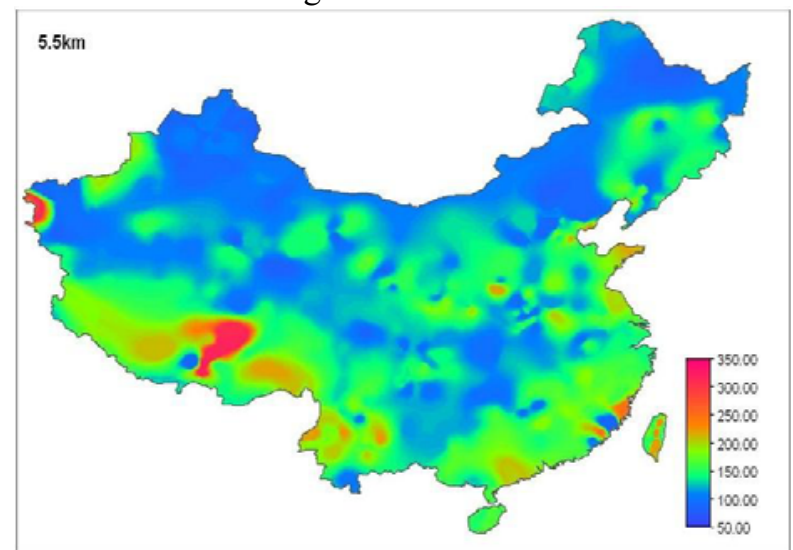

Figure 2. Land area $5.5 \mathrm{~km}$ deep geothermal resources distribution in China[10] 
The geothermal resources in China is quite rich, according to the preliminary evaluation, the conventional geothermal resources equals to 853 billion tons of standard coal resources in China, and the recoverable resources equals to 256 billion tons of standard coal, is mainly the medium and low temperature geothermal resources [11]. There are only two high temperature geothermal field in China, they are Yangbajing and Yangyi geothermal field, the rest are medium and low temperature geothermal field [12]. In the provinces (autonomous regions and municipalities), the most abundant geothermal resources is in Tibet autonomous region, the proven recoverable heat of geothermal resources is $1732.2 \mathrm{MW}$, followed by Yunnan, Guangdong, Hebei, Tianjin and other provinces (municipalities). The proven recoverable heat of the above five provinces (autonomous regions and municipalities) geothermal resources is $3157.1 \mathrm{MW}$, accounts for about three-quarters of the total geothermal resources in China.

\subsection{Geothermal resources exploration and evaluation status and problems}

Rich geothermal resources provide the foundation for speeding up the development of geothermal exploration technology in China, the current method used in geothermal exploration mainly are geothermal geology, remote sensing, geophysical, geochemical and isotope geology, drilling engineering and laboratory analysis, etc. $[13,14]$, but each method its theoretical and technical defects and deficiencies, so different geothermal resources exploration stages need different effective combination of methods to reduce the risk, the rationalize investment and improve economic benefit [15].

Shallow geothermal resource exploration and evaluation in China is officially starts pilot in 2006, in 2009 the ministry of land and resources introduced the "shallow geothermal energy exploration technical specification". Early work in Beijing, Tianjin, Shanghai and Hebei has completed preliminary investigation and evaluation work [16]. Due to complicated geological conditions in China, there are problems such as deep carving, complicated structure, poor physical property, great difficulty with exploration technical about deep geothermal resource. The main areas of deep geothermal exploration are mainly in northeast, north and northwest area, most of them are basin (transmitting) geothermal field, although some achievements has been obtained, but the basic theory system of geothermal geological remains to be further study. And from geothermal resource prediction, recognition to the output, compared with the developed countries, the exploration and development technology in China also has great disparity [17,18].

In general, the geothermal resource exploration and evaluation in China mainly exists following problems: (a) the low degree of geothermal resource exploration and evaluation around the country, lacking of unified exploration evaluation system, dynamic monitoring system and exploration and development planning, failing to form a systematic exploration and evaluation agency [19]. At present, the total geothermal resources has always been an approximate number, the unified data has not been recognized, especially in the western region in China and north China plain area, the normal geothermal exploration work has not been carried out [20]. (b) the shallow geothermal exploration seriously lags behind its development. (c) the exploration evaluation of deep geothermal resources under $2000 \mathrm{~m}$ has not been actualized and the resource extent is not clear. (d) the research on hot dry rock utilization technology has not been carried out $[21,22]$.

\subsection{Geothermal resources development and utilization situation and existing problems}

The utilization of geothermal resources is divided into two ways: one is geothermal power generation and its development is relatively slow. High temperature geothermal power is represented by Yangbajing, and medium-low temperature geothermal power generation only remaining in the Guangdong Fengshun and Hunan Huitang two power plants [23]. The other kind is the direct use of geothermal energy, including the direct use of geothermal water (such as geothermal heating, bathing, aquaculture, etc.) and ground source heat pump heating, cooling, [24, 25], among them bathing and 
spa account for $47.55 \%$, heating accounts for $30.77 \%$, other account for $21.68 \%$. In China, directly using of geothermal equipment capacity was $8898 \mathrm{mw}$ in 2010, ranking second in the world [26].

At present, the utilization of geothermal resources in China has formed geothermal power generation represented by the Tibet Yangbajing, geothermal heating represented by Tianjin, Xi 'an and Beijing, surface water source heat pump heating and refrigeration represented by Chongqing, sea water resource heat pump heating and refrigeration represented by Dalian, residents and tourism represented by southeast coast, as well as planting and breeding represented by the north China plain pattern of development and utilization.

Yangbajing Geothermal Power Plant, by utilizing recovered geothermal water, built up an $800 \mathrm{MW}$ screw expanding generator unit. The internal efficiency of such power generation systems has reached up to $70-80 \%$; when its load has a big change in range, its performance indicators fluctuate quite small; in addition, its equipment inlet design parameters are matched to that of the geothermal energy resource; it is the best geothermal power generation mode at present. Fig. 3 is the diagram of the Thermal system for Yangbajing Dual Medium Circulating Screw Expanding Power Generator Unit. Hot heat réservoirs Fields of Yambajan include two parts, which named shallow and deep, belong to the same two different parts of the water heating system. The first generating unit is successful on September in 1977 and installed capacity was expanded to 25MW by 1991, annual output can reach $1 \times 10^{8} \mathrm{KWh}$ [27].

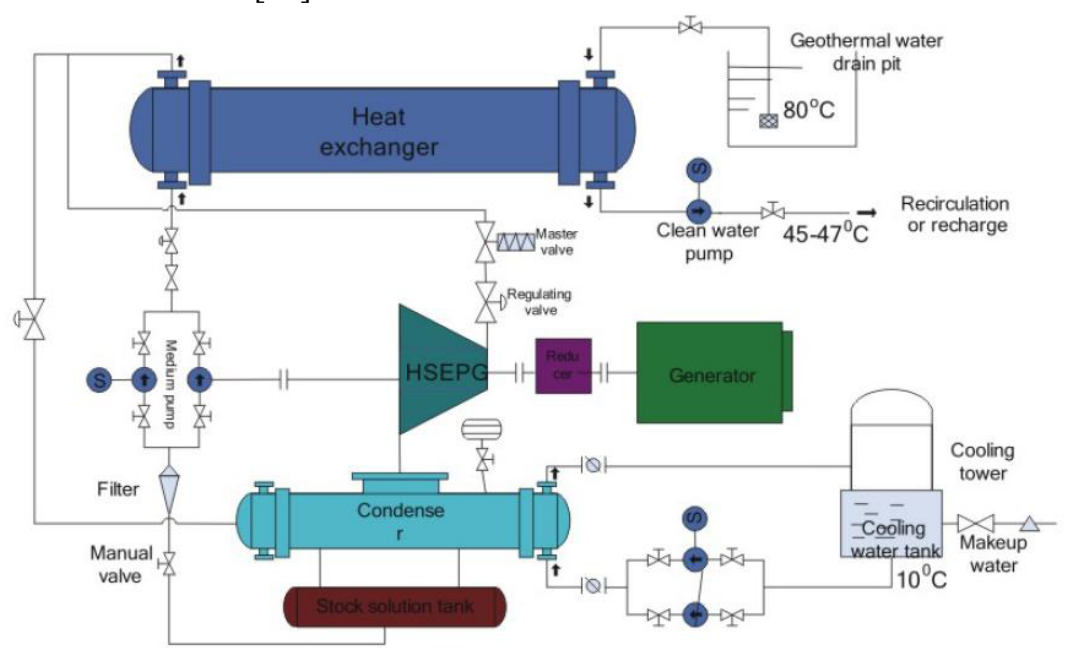

Figure 3. Diagram of the Thermal system for Yangbajing Dual Medium Circulating Screw Expanding Power Generator Unit [27].

Geothermal power is capital-intensive industry, so the initial investment is large enough, which is the total fee of all resource. Electric power generation which is based on the fossil fuels such as natural gas and coal cost too much fuel investments, but geothermal power once it is built down; there is no need any fee to support it. Table 1 is the the average cost of the budget for different power plants in 2016 [28].

Table1. The average cost of the budget for different power plants in 2016 [28]

\begin{tabular}{c|c|c|c|c|c|c}
\hline & \multirow{2}{*}{ Energy type } & \multicolumn{5}{|c}{ average cost budget for power plants in 2016} \\
\cline { 3 - 7 } & \multirow{2}{*}{$\begin{array}{c}\text { Energy } \\
\text { efficency } \\
(\%)\end{array}$} & $\begin{array}{l}\text { The main } \\
\text { body core } \\
\text { average } \\
\text { cost }\end{array}$ & $\begin{array}{l}\text { Maintenance } \\
\text { costs }\end{array}$ & $\begin{array}{l}\text { Variable } \\
\text { costs } \\
\text { (including } \\
\text { fuel) }\end{array}$ & $\begin{array}{l}\text { The } \\
\text { transmission } \\
\text { input }\end{array}$ & $\begin{array}{l}\text { System's overall cost } \\
\text { of homogenization }\end{array}$ \\
\hline traditional coal -fired & 85 & 65.3 & 3.9 & 24.3 & 1.2 & 94.8 \\
\hline Advanced coal-fired & 85 & 74.6 & 7.9 & 25.7 & 1.2 & 109.4 \\
\hline Advanced coal-fired With & 85 & 92.7 & 9.2 & 33.1 & 1.2 & 136.2 \\
\hline
\end{tabular}




\begin{tabular}{|c|c|c|c|c|c|c|c|}
\hline \multicolumn{8}{|c|}{ carbon dioxide capture } \\
\hline \multirow{5}{*}{$\begin{array}{l}\text { Natura } \\
1 \text { gas }\end{array}$} & $\begin{array}{c}\text { Traditional } \\
\text { combined cycle }\end{array}$ & 87 & 17.5 & 1.9 & 45.6 & 1.2 & 66.1 \\
\hline & $\begin{array}{c}\text { Advanced } \\
\text { combined cycle }\end{array}$ & 87 & 17.9 & 1.9 & 42.1 & 1.2 & 63.1 \\
\hline & $\begin{array}{c}\text { Advanced } \\
\text { combined cycle } \\
\text { With carbon } \\
\text { dioxide capture } \\
\end{array}$ & 87 & 34.6 & 3.9 & 49.6 & 1.2 & 89.3 \\
\hline & $\begin{array}{c}\text { Traditional gas } \\
\text { turbine }\end{array}$ & 30 & 45.8 & 3.7 & 71.5 & 3.5 & 124.5 \\
\hline & $\begin{array}{c}\text { Advanced gas } \\
\text { turbine }\end{array}$ & 30 & 31.6 & 5.5 & 62.9 & 3.5 & 103.5 \\
\hline \multicolumn{2}{|c|}{ Advanced nuclear power } & 90 & 90.1 & 11.1 & 11.7 & 1.0 & 113.9 \\
\hline \multicolumn{2}{|c|}{ Wind energy } & 34 & 83.9 & 9.6 & 0 & 3.5 & 97.0 \\
\hline \multicolumn{2}{|c|}{ Coastal wind power } & 34 & 209.3 & 28.1 & 0 & 5.9 & 243.2 \\
\hline \multicolumn{2}{|c|}{$\begin{array}{c}\text { solar photovoltaic power } \\
\text { generation }\end{array}$} & 25 & 194.6 & 12.1 & 0 & 4.0 & 210.7 \\
\hline \multicolumn{2}{|c|}{ solar-thermal } & 18 & 259.4 & 46.6 & 0 & 5.8 & 311.8 \\
\hline \multicolumn{2}{|c|}{ geothermal energy } & 92 & 79.3 & 11.9 & 9.5 & 1.0 & 101.7 \\
\hline \multicolumn{2}{|c|}{ biomass energy } & 83 & 55.3 & 13.7 & 42.3 & 1.3 & 112.5 \\
\hline \multicolumn{2}{|c|}{ hydro (electric) power } & 52 & 74.5 & 3.8 & 6.3 & 1.9 & 86.4 \\
\hline
\end{tabular}

Note: data from the U.S. energy information administration (EIA) annual energy outlook (2011), the cost budget through the existing capacity effectively in the grid can be calculated, not considering the preferential tax or incentives.

The main problems existing in the process of development and utilization of geothermal resource in China are as follows: (a) geothermal resource utilization rate is low, comprehensive benefit is not significant, waste of resources phenomenon is serious; (b) excessive mining in some areas and the phenomenon of environmental pollution and destruction [29].

\subsection{The current situation and existing problems of geothermal resources management}

In order to promote the development of geothermal technology and industry in China, a series of laws and regulations related to geothermal energy policy and technical specifications have been issued from national to local governments in recent years, mainly include: "mid long term development of renewable energy", "geothermal resources geology exploration specifications", "technical specification for the ground source heat pump system engineering", "geothermal power plant connected to the power system technical regulations", "technical specification for evaluation of the development of shallow geothermal energy" and "technical specification of geothermal heating project in town", etc. [30].

The geothermal resource management still exist a series of problems: (a) hysteresis of legislation, management function has not been put in place. Now in addition to part of provinces, national laws and regulations of geothermal resources development and utilization has not been issued and failed to form a certain legal system, management style, methods, and the administrative subject is also not clear [31]. (b) the geothermal resource management related technical measures did not reach the designated position, which influenced the management functions [32]. (c) National attention is not enough, lack of prophase investment, and incentives and incentive measures has not been introduced to promote its development [33].

\section{Current Research Review on Sustainable Development of The Geothermal Industry in China}

Take a wide view of academic research for the sustainable development of the geothermal energy industry in China, domestic scholars mainly put forward some managerial and technical suggestions on sustainable development research from geothermal resource development situation our country or regions the development situation, development and utilization of geothermal resources current situation and existing problems. 
From the perspective of management, Li xia [34] put forward that for the healthy development of geothermal industry in China, we should carry out reasonable planning of the development and utilization of geothermal resources, guide and standardize the industry development, actively develop the shallow geothermal energy resources exploration evaluation, promote the sustainable development of the industry, create a good policy environment, support the development of geothermal industry, increase the geothermal exploitation and utilization of the technology innovation, and improve the technical support system. Cheng Boyu [35] proposed that to realize the sustainable development of geothermal resources, we should exploit normatively, strengthen the construction of laws and regulations and the planning work and so on. XingQian [36] also thought we should reasonably planning the development and utilization of geothermal resources, strengthening the construction of relevant laws and regulations to realize the sustainable development and utilization of geothermal resources.

From a technical perspective, $\mathrm{Xu}$ junxiang [37] put forward to strengthen the exploration of geothermal resources evaluation, carry out "comprehensive utilization, step-by-step development", rely on high-tech, establish the demonstration area and promote the industrialization of geothermal. Sun jia[6] proposed the cascade utilization of geothermal resources to maximize the geothermal resource utilization, the application of the injection technology can protect the geothermal resources, improve resource utilization efficiency, reduce environmental pollution, and strengthen the geothermal water thermal insulation and heat exchange technology can effectively increase the geothermal water heat exchange efficiency. Lin Li [38], Zhou Dan [39] thought that increasing injection wells and improving injection rate is the important guarantee to realize sustainable development and utilization of geothermal resources. Zhang su'e [40] put forward to divide mining partition to realize the balanced development of the geothermal resources, and strictly control the exploitation quantity, reasonably plan geothermal well spacing to realize sustainable development and utilization of geothermal resources has important significance.

Besides, the domestic scholars' research on geothermal resources sustainable development index system is quite less. Su yong-qiang [41] chose Hebei hengshui city geothermal resources as the research object, established six subsystems of economy, society, resource, population, environment and science and education, used the Delphi method to determine the resource conditions, the development and utilization efficiency and management level as the three primary evaluation index, and respectively was subdivided into temperature flow, water quality, buried depth, distribution scope; Cascade utilization ratio, injection rate, water temperature, environmental pollution; Degree of exploration, dynamic detection rate, the scientific research level these eleven secondary evaluation index, and then based on Delphi method system, organized experts scoring, then applied fuzzy evaluation method comprehensively evaluated the sustainable development and utilization of geothermal resources in hengshui city, evaluation factors weights were determined by analytic hierarchy process, and according to the evaluation results, put forward the countermeasures of sustainable utilization of geothermal resources in hengshui city. Kong Weizhen [42] put three-e into the DEA model and established the economic evaluation model of geothermal resources.

\section{The Geothermal Industry Sustainable Development Research Problems and Research Direction in China}

Global geothermal resources within $5 \mathrm{~km}$ is about 4.9 trillion tons of standard coal, about one six of the global geothermal resource is in China. Studies have pointed out that, by 2020, Chinese non-fossil energy accounted for primary energy total consumption will increase to $15 \%$, geothermal resources development and utilization will reach 50 million tons of standard coal; in 2030 will reach 100 million tons of standard coal. The development and utilization of geothermal is of great significance for energy structure adjustment, energy conservation and emissions reduction in China. At present, the geothermal utilization in our country is still in its infancy, and the sustainable development of geothermal industry research also exists many problems, such as lacking of thorough research on the 
geothermal industry sustainable development connotation, theoretical framework, evaluation system and methods of research.

Integrated the current situation and existing problems of the geothermal industry sustainable development in China, the following several aspects can be studied in-depth in the future: (1) define the geothermal industry sustainable development connotation and point out the factors influencing the geothermal industry sustainable development in China; (2) combined with the particularity of the geothermal industry, on the basis of the existing index system of sustainable development, put forward the scientific research methods, build the evaluation index system of sustainable development of geothermal industry development in China, and carry out comprehensive evaluation of the geothermal industry sustainable development ability; (3) put forward the path and countermeasures for the sustainable development of geothermal industry in China .

\section{References}

1. H.L. Zhang, Research on the New Energy Development in China, Jilin University, 1 (2014)

2. X. Guan, The situation, measures \& suggestions on the exploration and utilization of geothermal resources, CMM, 5, 78-84 (2010)

3. W.J. You, Y.F. Liu, M.J. Guo, Environmental Issues in the Development and Utilization of Geothermal Resources. Safety and Environmental Engineering, 20, 24-28 (2013)

4. S.G. Xu, Y.S. Guo. Geothermics basis (Science press. 2009)

5. Z.L. Liao, Y.J. Zhang, W.B. Chen,et al. Available persist exploitation and utilization of geothermal resources, China Mining Magazine, 15, 8 11 (2006)

6. G.H.Zhou,R.Huang,P.P.Xie. Component analysis of geothermal industry, Scientific and Technological Management of Land and Resources,30,47-53, (2013)

7. J. Sun, Available persist exploitation and utilization of geothermal resources, Resources Economization \& Environmental Protection, 4, 11 (2006)

8. J.H. Zhang, W. Wei, D. Du,et al. The Development, Utilization and Sustainable Development of Geothermal Resources, Sino-Global Energy, 18, 30-35, (2013)

9. X. Guan, Study on method and application of economic evaluation of geothermal resources, CUG, 8-10 (2014)

10. W.J. Lin, Z.M. Liu, W.L.Wang, et al.The assessment of geothermal resources potential of China, Geology in China, 40, 312-321 (2013)

11. J.H. Zhang, Geothermal resource distribution and utilization of our country, Natural Resource Economics of China, 8, 23-24 (2011)

12. X.J. Kong, Z.T. Sun, L.Z. Yuan, et al. Application of Large Aperture DTH Drilling Technology in Dewatering of Subway Engineering, City Geology, 9, 14-16 (2014)

13. L. Ding, S.J. Song, J. Guan, et al.Geothermal resource exploration technique application and prospect, Jilin Geology, 4, 113-117 (2004)

14. J.X.Wu, The integrated use of various technology in geothermal exploration method, Ground Water, 35, 105-109 (2013)

15. J.Q. Xu, C.J. Bai, Y.F. Wang, Technique application of geothermal resources exploration in China, Henan earth science bulletin, 444-448 (2009)

16. G.Y. Liu, G.H. Li, Y. Zhang, Geothermal resource exploration and development present situation and countermeasure research, Natural Resource Economics of China, 10, 17-20 (2010)

17. B. Sun, An Opinion on Cognition and Exploration Method of Deep Geothermal Resources in China, Coal Geology of China, 1, 20-22 (2006)

18. S.Z. Wang, Y.Wang, The basic actuality and the countermove of deep-layer geothermal resources exploring in our country, Journal of Hebei University of Engineering(Natural Science Edition), 3, $72-74(2002)$

19. X.G. Zhao, G. Wan, Current situation and prospect of China's geothermal resources, Renewable and Sustainable Energy Reviews, 32, 651-661 (2014) 
20. X.C. You, S.Z. Yao, Utilization State and Protection Project in China Geothermal Area, China Mining Magazine, 6, 1-3 (2007)

21. X.Y. Wang, H.M. Li, The use of geothermal energy analysis and development prospects, Energy Research \& Utilization, 3, 45-58 (2013)

22. Y. Feng, X. Chen, X.F. Xu, Current status and potentials of enhanced geothermal system in China, Renewable and Sustainable Energy Reviews, 33, 214-223 (2014)

23. Q. Zhan, Y. Cui, The present situation and prospect analysis of geothermal resources development and utilization in China, Theory Monthly, 8, 170-172 (2010)

24. L.X. Ma, S. Tian, The geothermal energy exploitation and utilization present situation and the development in China, Natural Resource Economics of China, 9, 19-21 (2006)

25. L. Li, X. Li, Geothermal energy utilization present situation and development prospect of China, Heilongjiang Science and Technology Information, 26, 11 (2011)

26. W.H. Zhou, The Status Analysis of China's Geothermal Power Generation, Petroleum \& Petrochemical Today, 8, 22-27 (2013)

27. Ministry of Science and Technology of the People's Republic of China.China's geothermal energy utilization, http://www.most.gov.cn/kjbgz/201203/t20120309 93106.htm,03,12,2012.

28. F.G.Liu,D.Hu,M.Wu ,et al. Economic Analysis on Investment in Geothermal Power Generation, SINO-GLOBAL ENERGY,19,24-30(2014)

29. J.J. Jiang, Q.F. Tao, J. Hu, The utilization of geothermal resources, existing problems and suggestion in China, National conference on sustainable development of the geothermal industry (2005)

30. X. Guan, Chinese Geothermal Development in the Future, City Geology, 7, 6-8 (2012)

31. X. Guan, Draw lessons from foreign experience in promoting the geothermal industry policy development in China, Hydrogeology \& Engineering Geology, 38, 1-4 (2011)

32. H.Y. Cui, Some thinking for geothermal resources management in Shanxi province, Huabei Land and Resources, 3, 20-21 (2014)

33. Y.L. Gong, W.B. Ma, Analysis of geothermal energy technology application present situation and the industry in China, High-Technology \& Industrialization, 7, 34-35 (2008)

34. X. Li, The geothermal industry problems and Suggestions, Heating \& Refrigeration, 5, 58 (2012)

35. B.Y. Cheng, Geothermal Resources and Its Sustainable Development in Hubei Province, Resources Environment \& Engineering, 21, 107-110 (2007)

36. Q. Xing, The geothermal industry sustainable development path analysis, Chemical Enterprise Management, 14, 7-9 (2013)

37. J.X. Xu, China's Geothermal Resources and Its Sustainable Development and Utilization, China Population, Resources and Environment, 15, 139-141 (2005)

38. L. Lin, S.M. Zhao, P. Li, et al. The countermeasures for the sustainable development and utilization of geothermal resources in Tianjin, Natural Resource Economics of China, 12, 7-10 (2005)

39. D. Zhou, The Cascaded Exploitation and Sustainable Utiliation of Geotheimal Resource, Science \& Technology Information, 19, 128 (2014)

40. S.E. Zhang, Z.J. Li, X.Z. Zheng, Sustainable development strategy of geotbeanal resource and protection proposals, Journal of Geology, 34, 220-224 (2010)

41. Y.Q. Su, The geothermal resoUrces continuable development and investination in Hengshui City, Tianjin University, 8-9 (2009)

42. W.Z. Kong, A Dissertation Submitted to ChinaUniversity of Geosciences for the Doctor Degree of Resources Industrial Economics, China University of Geosciences, 10 (2014) 